Article

\title{
Improving People's Self-Reported Experience with the Health Services: The Role of Non-Clinical Factors
}

\author{
Ángel Fernández-Pérez *(1) and Ángeles Sánchez \\ Department of Applied Economics, University of Granada (Spain), Faculty of Economics and Business Science, \\ Campus Cartuja s/n, 18071 Granada, Spain; sancheza@ugr.es \\ * Correspondence: angelfp@ugr.es; Tel.: +34-958-24-95-75
}

Received: 2 December 2019; Accepted: 21 December 2019; Published: 25 December 2019

check for updates

\begin{abstract}
The main aim of this study was to analyse the association between non-clinical factors and the self-reported experience of people with the main health services of the Spanish public healthcare system. Specifically, we analysed whether factors such as the treatment received from health staff, the confidence transmitted to the patient by the doctor, or waiting time for a diagnostic test had an influence on people reporting a more satisfactory experience with primary, specialised, and hospital care services. We used cross-sectional microdata from the Spanish Healthcare Barometer survey of 2015 comprising a sample of 7800 individuals. We applied a probit-adapted ordinary least squares estimation, which is one of the most widely used methods in recent studies on subjective well-being. Our findings suggest that individuals' interaction with non-clinical factors was positively correlated with the overall health services experience. Treatment received from health staff was one of the most relevant factors to ensure that individuals report a more satisfactory experience with primary care. Time devoted by physicians to each patient and waiting time for a non-emergency admission were the most correlated factors in specialised and hospital care services, respectively. This study could have implications for public policies. First, it shows policy-makers the influence of non-clinical factors when individuals rate their overall experience with the main health services in Spain. Second, it identifies the key factors where the health system could reallocate more public resources to improve people's experience and thus the health system responsiveness.
\end{abstract}

Keywords: public policies; health economics; responsiveness; health system performance; primary care; specialised care; hospital care; POLS

\section{Introduction}

In 2000, the World Health Organization (WHO) published Health Systems: Improving Performance, a report that underscored the pressing need to assess health system performance [1]. In the report, the WHO developed a framework for assessing the overall performance of a health system taking into account the following items: level and distribution of health, level and distribution of responsiveness, and fairness in financial contribution. Of these items, those related to responsiveness have received increasing attention in the literature [2-5]. Health system responsiveness concerns the way individuals are treated and the environment in which they are treated by the health system. Responsiveness is related to the so-called non-clinical factors, an aspect that, although not directly related to health outcomes, may be equally important to guarantee the well-being of the population [6,7]. In addition to ensuring people's health, treating them with dignity, taking into account their opinion, providing them proper information about their health problems, or attending to them promptly are fundamental objectives of any health system. The WHO has developed eight domains in which most non-clinical factors can be classified: autonomy, choice, communication, confidentiality, dignity, prompt attention, quality of basic amenities, and access to family and social support [6]. 
The importance of responsiveness stems mainly from its relation to people's health $[6,8,9]$. Ensuring better experiences with non-clinical factors could lead individuals to be more cooperative with their health problems, accept treatment procedures, or follow the advice of health staff $[10,11]$. In developing countries, it has been shown that a lack of responsiveness in health systems can lead to an underutilisation of the health services and cause declining health [12]. Additionally, responsiveness is fundamental due to its relationship with human and patients' rights [13].

As some authors have stated, it is difficult to use objective indicators to measure non-clinical factors [6]. For instance, it is not easy to measure the level of dignity or autonomy with which a health system treats its population in a direct way with an objective indicator. Therefore, the experiences that people report with regard to non-clinical factors have typically been used to quantify the level of health system responsiveness in these domains. Some authors have shown that subjective measures may be a good proxy of the real responsiveness of health systems [2].

Given the importance of responsiveness, all the factors or domains related to this concept should be addressed by health systems. However, recent budgetary constraints in health care provision in the wake of the economic crisis have led to a growing concern about the efficient use of public resources [14,15]. Accordingly, health policy-makers have to decide which non-clinical factors are a priority in order to receive more resources to improve users' experience with the health system. For instance, should we invest more in reducing waiting times, or would it be better to invest more in improving the communication skills of doctors?

The main aim of this paper was to analyse the association between non-clinical factors and the self-reported experience of people with each of the main health services of the Spanish public healthcare system. Specifically, we identified the most influential non-clinical factors to ensure patients report an overall satisfactory experience with primary (general practitioner), specialised (outpatient care), and hospital care (inpatient care) services. We have also checked whether these factors are the same across health services or if they change depending on the specific service analysed. In addition to measuring the level of responsiveness with each of the non-clinical factors, the findings of this study provide empirical evidence about the role that these factors play in shaping people's overall experience with the main health services in Spain. In this vein, these results could aid policy-makers in determining which non-clinical factors should be allocated more resources to significantly improve patients' experience with each health service and hence enhance the overall performance of the Spanish health system. Public health expenditure in Spain accounted for $71.1 \%$ of total health expenditure in 2015, whereas private spending accounted for the remaining $28.9 \%$ [16]. Therefore, our analysis covered a significant part of the Spanish health system.

To the best of our knowledge, this is the first study to analyse the role of non-clinical factors for three of Spain's main health services. Although several studies have examined the influence of non-clinical factors on patient satisfaction, the analyses were confined to certain regional health services [17,18] or to a specific health service [19-22]. Studies addressing self-reported levels of overall satisfaction with the health system or its services in Spain have primarily examined the influence of socioeconomic or organisational factors. However, the potential effects of non-clinical factors on overall satisfaction have not yet been analysed [23]. Likewise, from the international point of view, studies taking into account non-clinical factors have mainly focused on analysing the influence of these factors on patients' satisfaction with a health service [24-26].

\section{Materials and Methods}

This study uses cross-sectional microdata obtained from the Spanish Healthcare Barometer (SHB) survey of 2015 conducted by the Spanish Centre for Sociological Research in coordination with the Spanish Ministry of Health since 1993. This annual survey collects the opinions of citizens 18 years of age and over on several aspects of the health services of the Spanish National Health System (SNS). Data are gathered using a structured questionnaire administered by means of a personal interview in the respondents' households. The annual survey is conducted in three waves with a total sample of 
about 7800 respondents and is representative of the Spanish adult population with a sample error of $\pm 1.14 \%$. The survey uses a multistage sampling procedure stratified by cluster with randomly selected sampling units.

The principle feature of the SHB survey is that the respondents are asked to assess their overall experience with the main Spanish public health services (primary, specialised, and hospital care). The respondents are asked the following question: 'Based on your own experience or opinion, please rate the following public health services: primary care consultations; specialised care consultations; admission and care in public hospitals'. Respondents rate their experience with each health service on a scale of 1 to 10 where 1 is 'completely unsatisfactory' and 10 is 'completely satisfactory'.

Likewise, the survey provides information on the degree to which the health services respond to a series of non-clinical factors with which citizens interact. Specifically, we analysed nine items for primary care, seven for specialised care, and six for hospital care These non-clinical factors were assessed according to the respondents' experience or opinion with each factor on a 10-point scale where 1 is 'completely unsatisfactory' and 10 is 'completely satisfactory'. Table 1 shows the 13 non-clinical factors analysed in this study (Column 1), the questions that respondents answered in the SHB survey to rate their experience with each of the 13 non-clinical factors (Column 2) as well as the health services each non-clinical factor refers to (Column 3 ).

Table 1. Non-clinical factors included in the Spanish Healthcare Barometer by health service in 2015.

\begin{tabular}{|c|c|c|}
\hline Non-Clinical Factor & $\begin{array}{c}\text { Question in the SHB Survey: } \\
\text { Based on Your Own Experience or Opinion, Please } \\
\text { Rate the Following Items: ... }\end{array}$ & Health Service ${ }^{1}$ \\
\hline Time devoted by doctor & The time devoted by the doctor to each patient & Primary Specialised \\
\hline Confidence and security & $\begin{array}{l}\text { The confidence and security transmitted by } \\
\text { the doctor }\end{array}$ & Primary Specialised \\
\hline $\begin{array}{l}\text { Knowledge and follow-up of } \\
\text { health problems }\end{array}$ & $\begin{array}{l}\text { Knowledge of medical records and follow-up of } \\
\text { health problems }\end{array}$ & Primary \\
\hline $\begin{array}{l}\text { Information received on } \\
\text { health problem }\end{array}$ & The information received on your health problem & Primary Specialised Hospital \\
\hline Advice of doctor & $\begin{array}{l}\text { Advice of the doctor about exercise, diet, smoking, } \\
\text { alcohol consumption, etc. }\end{array}$ & Primary Specialised Hospital \\
\hline Waiting time for diagnostic tests & The waiting time for carrying out diagnostic tests & Primary Specialised \\
\hline Care by nursing staff & The care delivered by nursing staff & Primary \\
\hline $\begin{array}{l}\text { Waiting time for non-emergency } \\
\text { admission }\end{array}$ & The waiting time for a non-emergency admission & Hospital \\
\hline $\begin{array}{l}\text { Care and attention by } \\
\text { medical staff }\end{array}$ & The care and attention delivered by medical staff & Hospital \\
\hline $\begin{array}{l}\text { Care and attention by } \\
\text { nursing staff }\end{array}$ & The care and attention delivered by nursing staff & Hospital \\
\hline
\end{tabular}

We also used a set of the respondents' socioeconomic characteristics commonly applied in the literature and provided by the SHB survey. Specifically, we considered the following 10 variables: age (Aged 60); gender (Female); level of education (Higher education); marital status (Single); place of residence (Urban); place of birth (Born abroad); occupational status (Employed); self-reported health (Good health); self-reported chronic illness (Chronically ill); and experience with public health service (see Table 2). 
Table 2. Socioeconomic variables of respondents to analyse self-reported experience with the public Spanish health services in 2015.

\begin{tabular}{|c|c|}
\hline Variable & Definition \\
\hline Aged60 & 1 if respondent is aged over 60 and 0 otherwise \\
\hline Female & $1=$ female, $0=$ male \\
\hline Higher education & $\begin{array}{l}1 \text { if respondent has secondary or tertiary education and } 0 \text { if } \\
\text { respondent has primary education or no schooling }\end{array}$ \\
\hline Single & $\begin{array}{l}1 \text { if respondent is single and } 0 \text { if respondent is married, } \\
\text { widowed, separated, or divorced }\end{array}$ \\
\hline Urban & $\begin{array}{l}1 \text { if respondent lives in a city with over 10,000 inhabitants and } \\
\qquad 0 \text { otherwise (rural) }\end{array}$ \\
\hline Born abroad & 1 if respondent was not born in Spain and 0 otherwise \\
\hline Employed & 1 if respondent is employed and 0 otherwise \\
\hline Good health & $\begin{array}{l}1 \text { if respondent perceives his/her state of health as good or very } \\
\text { good and } 0 \text { otherwise }\end{array}$ \\
\hline Chronically ill & 1 if respondent reports being chronically ill and 0 otherwise \\
\hline Experience with public health service & $\begin{array}{l}1 \text { if respondent has used, at least once, the Spanish public health } \\
\text { service in the last } 12 \text { months and } 0 \text { otherwise }\end{array}$ \\
\hline
\end{tabular}

Note: Centre for Sociological Research, Spanish Healthcare Barometer survey, 2015.

In order to determine the association between non-clinical factors and the self-reported experience of respondents with each of the three Spanish health services (i.e., primary, specialised, and hospital care), we propose the following model:

$$
Y=\alpha+X \beta+Z \rho+R \lambda+\varepsilon
$$

where $\mathrm{Y}$ is the vector of the dependent variable self-reported experience with the health service of $\mathrm{n}$ individuals and $\mathrm{X}$ is a matrix containing the set of non-clinical factors. Let $\beta$ denote a vector of parameters where $\beta=\left(\beta_{1}, \ldots, \beta_{9}\right)^{\prime}$ is primary care, $\beta=\left(\beta_{1}, \ldots, \beta_{7}\right)^{\prime}$ is specialised care, and $\beta=\left(\beta_{1}\right.$, $\left.\ldots, \beta_{6}\right)^{\prime}$ is hospital care. $Z$ denotes the socioeconomic characteristics; $\varrho$ denotes a vector of parameters $\varrho=\left(\varrho_{1}, \ldots, \varrho_{10}\right)^{\prime} ; \mathrm{R}$ is the set of regional dummies; and $\varepsilon$ is the error term that is assumed to have a normal distribution of zero mean and $\sigma^{2}$ variance.

Given that we analysed three health services, we ran model (1) three times, one for each health service. We worked with 6252 observations for primary care, 5854 for specialised care, and 4702 for hospital care. We included all respondents without missing values in the studied variables.

Our parameters of interest were represented by vector $\beta$ in model (1), which indicates the level of correlation between the self-reported experience with each non-clinical factor and the overall self-reported experience with each health service.

We estimated model (1) using probit-adapted ordinary least squares (POLS) [27]. POLS is a method that is being increasingly used in the most recent literature on subjective well-being [28-32]. The POLS method estimates coefficients using ordinary least squares (OLS) instead of an ordered probit $(\mathrm{OP})$ or ordered logit (OL) method for regression models where the dependent variable is ordered categorically. This method has several outstanding advantages. Whereas POLS and OP yield roughly the same results regarding the sign and significant of the coefficients [27], POLS requires much less computing time and is much easier to understand. First, it facilitates the interpretation of coefficients since they can be directly interpreted as OLS coefficients instead of probabilities. Second, when the model considers the interaction between explanatory variables, its interpretation is not easy in the OP or OL models, whereas POLS facilitates the interpretation [30]. Finally, the cardinalisation process can also be applied in explanatory variables representing ordered categories [27-29]. For our study, this aspect is crucial. If the OP or OL method is used instead of POLS, nine dummies (10 categories 
minus 1) must be included in Equation (1) as explanatory variables for each of the non-clinical factors analysed in the model. For example, in the case of primary care, it would be necessary to include 81 dummy variables (nine non-clinical factors multiplied by nine dummies).

The POLS method is applied in two stages. In the first stage, the dependent and explanatory variables are changed from ordinal to cardinal values, known as the 'cardinalisation process'. In the second stage, the OLS estimation is applied to the new transformed variables.

In the cardinalisation process, the POLS method draws on the implicit cardinalisation of $\mathrm{y}_{\mathrm{i}}{ }^{*}$ (a continuous unobserved variable) of the latent variable model of the OP or OL methods to transform the observed variable (y), which only takes ordered integer values from 1 to 10 (our response categories), into a variable that is able to take any value on the real line $(-\infty,+\infty)(\bar{y})$. In order to cardinalise, it is necessary to carry out an increasing monotonic transformation to preserve the order of the response categories of the variables. In line with [27] (pp. 28-34), we used the normal distribution in our study. For this reason, we assumed that our three dependent variables $Y$ will be approximately normally distributed. Figure 1 shows the distribution of frequencies of the overall self-reported experience with each of the health services. The three services were skewed slightly towards positive values although their distributions were similar to the normal distribution. Regarding primary care, more than $90 \%$ of the respondents rated the service with a score of 5 or more and around $50 \%$ of the respondents gave a rating of 8,9 , and 10 . In specialised and hospital care, the values were more centred, since most of the responses $(70 \%)$ were in the central categories $5-8$.

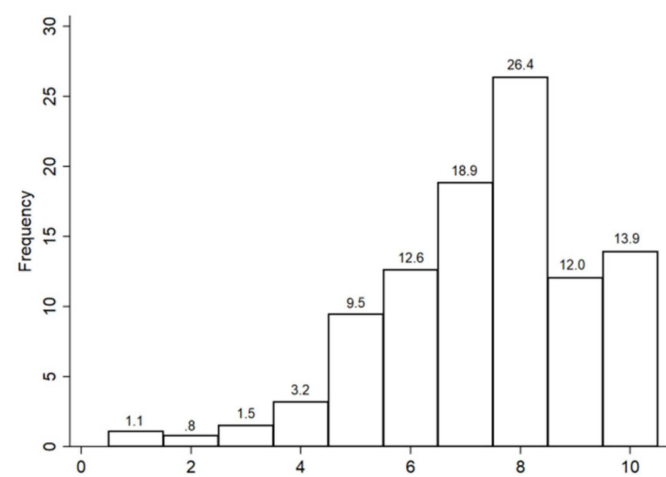

(a)

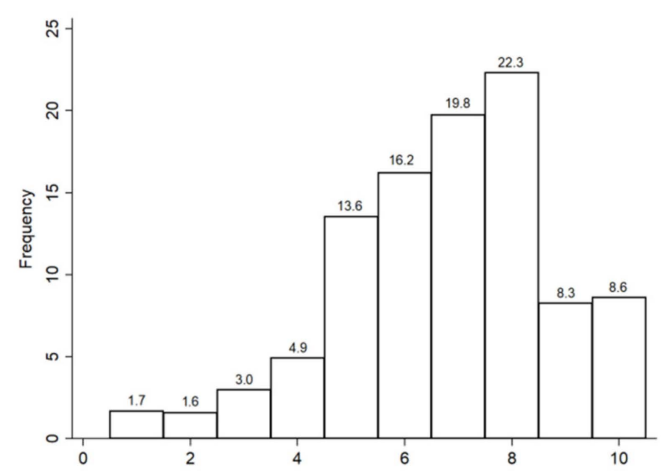

(b)

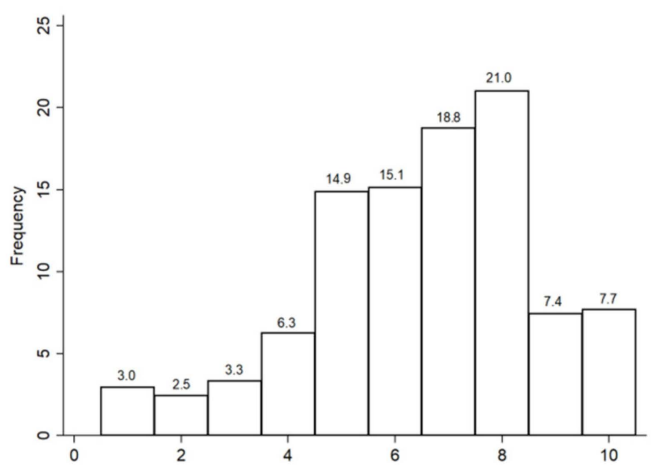

(c)

Figure 1. Distribution of frequencies of the overall self-reported experience with the Spanish health services: (a) Primary care; (b) Specialised care; (c) Hospital care. Data from the Spanish Centre for Sociological Research, Spanish Healthcare Barometer survey, 2015.

The transformation was performed taking into account the relative and absolute frequencies of the J response categories of the ordered variables as well as the values of the standard normal distribution function. We first obtained the $\mu_{\mathrm{j}}$ values (cut-points in the OP method). These values were associated to the standard normal distribution function from accumulated frequencies of the J response categories 
of the ordered categorical variables $\left\{\mu_{j}\right\}_{j}=0$ with $\mu_{0}=-\infty$ and $\mu_{\mathrm{J}}=+\infty$. Then, we calculated the conditional expectation of the unobserved variable for each of the response categories. Therefore, if the continuous unobserved variable of individual i is $y_{i}{ }^{*}$, where the observed variable is $y_{i}=j$ if $\mu_{j-1}<y_{i}{ }^{*}<$ $\mu_{j}$ for all $j=1, \ldots, J$, in accordance with the normal distribution theory, the conditional expectation of the unobserved variable would be:

$$
\bar{y}_{i}=E\left(y_{i}^{*} \mid \mu_{j-1}<y_{i}^{*}<\mu_{j}\right)=\frac{n\left(\mu_{j-1}\right)-n\left(\mu_{j}\right)}{N\left(\mu_{j}\right)-N\left(\mu_{j-1}\right)}
$$

where $\bar{y}_{i}$ is the cardinalisation of the dependent variable; $\mathrm{n}(\cdot)$ is the standard normal density function; and $\mathrm{N}(\cdot)$ is the accumulated normal distribution function.

Given that non-clinical factors in the X matrix of model (1) are also measured on a scale of 1 to 10 , we also applied Equation (2) in order to cardinalise them.

\section{Results}

Tables $3-5$ show the descriptive statistics of all the variables analysed in this study. Primary care was the highest rated health service with a mean score of 7.3, while hospital care showed the worst rating with a mean score of 6.5 (see Table 3). With regard to non-clinical factors, confidence and security (primary care), treatment received from health staff (specialised care), and care and attention delivered by nursing staff (hospital care) were the items with which the respondents had the most satisfactory experience. Conversely, items related to waiting times were the most poorly rated out of all health services (see Table 4).

Table 3. Descriptive statistics of the respondents' self-reported experience with each Spanish health service in 2015.

\begin{tabular}{ccccc}
\hline Type of Healthcare & N & Mean & SD & Min-Max \\
\hline Primary & 6252 & 7.3 & 1.8 & $1-10$ \\
Specialised & 5854 & 6.8 & 2.0 & $1-10$ \\
Hospital & 4702 & 6.5 & 2.1 & $1-10$ \\
\hline
\end{tabular}

Note: SD = Standard deviation; Min = Minimum; Max = Maximum. Adapted from the Spanish Centre for Sociological Research, Spanish Healthcare Barometer survey, 2015.

Table 4. Descriptive statistics of non-clinical factors by public health service in Spain in 2015.

\begin{tabular}{ccc}
\hline Non-Clinical Factors & Mean & SD \\
\hline Primary care 1 & & \\
Treatment received & 7.6 & 1.7 \\
Time devoted by doctor & 7.1 & 2.0 \\
Confidence and security & 7.7 & 1.9 \\
Knowledge and follow-up of health problems & 7.5 & 1.9 \\
Information received on health problem & 7.5 & 1.9 \\
Advice of doctor & 7.4 & 2.1 \\
Waiting time for appointments & 6.6 & 2.2 \\
Waiting time for diagnostic tests & 5.7 & 2.3 \\
Care by nursing staff & 7.4 & 1.8 \\
Specialised care 2 & & \\
Treatment received & 7.3 & 1.8 \\
Time devoted by doctor & 6.7 & 1.9 \\
Confidence and security & 7.2 & 1.9 \\
Information received on health problem & 7.1 & 2.0 \\
\hline
\end{tabular}


Table 4. Cont.

\begin{tabular}{ccc}
\hline Non-Clinical Factors & Mean & SD \\
\hline Advice of doctor & 6.9 & 2.1 \\
Waiting time for appointments & 5.1 & 2.3 \\
Waiting time for diagnostic tests & 5.0 & 2.3 \\
Hospital care 3 & & \\
Waiting time for non-emergency admission & 4.8 & 2.2 \\
Care and attention by medical staff & 7.2 & 1.9 \\
Care and attention by nursing staff & 7.3 & 1.8 \\
Number of people sharing room & 5.7 & 2.3 \\
Information received on health problem & 7.2 & 1.9 \\
Advice of doctor & 7.0 & 2.0 \\
\hline
\end{tabular}

Note: $\mathrm{SD}=$ Standard deviation. Responses are rated on a scale of 1-10 where 1 is 'completely unsatisfactory' and 10 is 'completely satisfactory'. Adapted from the Spanish Centre for Sociological Research, Spanish Healthcare Barometer survey, $2015 .{ }^{1} \mathrm{~N}=6252 ;{ }^{2} \mathrm{~N}=5854 ;{ }^{3} \mathrm{~N}=4702$.

Table 5. Descriptive statistics of respondents' socioeconomic characteristics, 2015.

\begin{tabular}{|c|c|c|c|c|c|c|}
\hline \multirow{3}{*}{ Variables } & \multicolumn{6}{|c|}{ Health Service } \\
\hline & \multicolumn{2}{|c|}{ Primary $^{1}$} & \multicolumn{2}{|c|}{ Specialised $^{2}$} & \multicolumn{2}{|c|}{ Hospital $^{3}$} \\
\hline & Mean & SD & Mean & SD & Mean & SD \\
\hline Aged60 & 0.28 & 0.45 & 0.28 & 0.45 & 0.28 & 0.45 \\
\hline Female & 0.52 & 0.50 & 0.53 & 0.50 & 0.52 & 0.50 \\
\hline Higher education & 0.75 & 0.43 & 0.75 & 0.43 & 0.76 & 0.43 \\
\hline Single & 0.31 & 0.46 & 0.31 & 0.46 & 0.30 & 0.46 \\
\hline Urban & 0.79 & 0.40 & 0.80 & 0.40 & 0.79 & 0.40 \\
\hline Born abroad & 0.11 & 0.31 & 0.10 & 0.30 & 0.10 & 0.30 \\
\hline Employed & 0.43 & 0.49 & 0.43 & 0.50 & 0.44 & 0.50 \\
\hline Good health & 0.74 & 0.44 & 0.73 & 0.45 & 0.73 & 0.44 \\
\hline Chronically ill & 0.32 & 0.47 & 0.33 & 0.47 & 0.33 & 0.47 \\
\hline \multicolumn{7}{|c|}{ Experience with public } \\
\hline Primary care & 0.72 & 0.45 & & & & \\
\hline Specialised care & & & 0.42 & 0.49 & & \\
\hline Hospital care & & & & & 0.09 & 0.29 \\
\hline
\end{tabular}

Note: SD = Standard deviation. Adapted from the Spanish Centre for Sociological Research, Spanish Healthcare Barometer survey, 2015. ${ }^{1} \mathrm{~N}=6252 ;{ }^{2} \mathrm{~N}=5854 ;{ }^{3} \mathrm{~N}=4702$.

Table 6 shows the results of the estimations with the regression results for each of the three Spanish public health services analysed: primary, specialised, and hospital care. After checking the corresponding tests, we did not detect problems of heteroskedasticity (corrected by the robust standard errors after using weights), multicollinearity (tested using the variance inflation factor), or omitted variables (Ramsey test). The results of the tests are available upon request.

The results in Table 6 indicate that the coefficients of all the non-clinical factors were positive and statistically significant in all health services, with the exception of advice of doctor in specialised and hospital care, and knowledge and follow-up of health problems in primary care, which were not significant. This indicates that the more satisfactory the self-reported experience with non-clinical factors, the more satisfactory the experience with the health services as a whole. 
Table 6. Determinants of overall self-reported experience with the Spanish public health services in 2015.

\begin{tabular}{|c|c|c|c|}
\hline & \multicolumn{3}{|c|}{ Health Service } \\
\hline & Primary & Specialised & Hospital \\
\hline Non-clinical factors & & & \\
\hline Advice of doctor & $\begin{array}{l}0.054^{*} \\
(0.022)\end{array}$ & $\begin{array}{c}0.031 \\
(0.023)\end{array}$ & $\begin{array}{c}0.042 \\
(0.025)\end{array}$ \\
\hline Confidence and security & $\begin{array}{c}0.172^{* * *} \\
(0.027)\end{array}$ & $\begin{array}{c}0.121^{* * * *} \\
(0.030)\end{array}$ & \\
\hline Time devoted by doctor & $\begin{array}{c}0.095^{* * *} \\
(0.021)\end{array}$ & $\begin{array}{c}0.164^{* * *} \\
(0.024)\end{array}$ & \\
\hline Knowledge and follow-up of health problems & $\begin{array}{l}-0.012 \\
(0.026)\end{array}$ & & \\
\hline Information received on health problem & $\begin{array}{c}0.128^{* * *} \\
(0.029)\end{array}$ & $\begin{array}{c}0.085^{* *} \\
(0.029)\end{array}$ & $\begin{array}{c}0.175^{* * *} \\
(0.028)\end{array}$ \\
\hline Treatment received & $\begin{array}{c}0.215^{* * *} \\
(0.021)\end{array}$ & $\begin{array}{c}0.127^{* * * *} \\
(0.026)\end{array}$ & \\
\hline Care by nursing staff & $\begin{array}{c}0.063 * * * \\
(0.019)\end{array}$ & & \\
\hline Care and attention by medical staff & & & $\begin{array}{c}0.152 * * * \\
(0.030)\end{array}$ \\
\hline Care and attention by nursing staff & & & $\begin{array}{c}0.124^{* * *} \\
(0.028)\end{array}$ \\
\hline Waiting time for appointments & $\begin{array}{c}0.084^{* * *} \\
(0.018)\end{array}$ & $\begin{array}{c}0.103 * * * \\
(0.025)\end{array}$ & \\
\hline Waiting time for diagnostic tests & $\begin{array}{l}0.039 * \\
(0.016)\end{array}$ & $\begin{array}{c}0.116^{* * *} \\
(0.025)\end{array}$ & \\
\hline Waiting time for non-emergency admission & & & $\begin{array}{c}0.181 * * * \\
(0.017)\end{array}$ \\
\hline Number of people sharing room & & & $\begin{array}{c}0.001 * * * \\
(0.017)\end{array}$ \\
\hline Socioeconomic variables & & & \\
\hline Female & $\begin{array}{l}0.039 \text { * } \\
(0.019)\end{array}$ & $\begin{array}{l}-0.021 \\
(0.022)\end{array}$ & $\begin{array}{l}-0.011 \\
(0.025)\end{array}$ \\
\hline Higher education & $\begin{array}{c}-0.093^{* * *} \\
(0.028)\end{array}$ & $\begin{array}{l}-0.058 \\
(0.033)\end{array}$ & $\begin{array}{c}-0.081 \text { * } \\
(0.040)\end{array}$ \\
\hline Urban & $\begin{array}{c}0.074^{* *} \\
(0.025)\end{array}$ & $\begin{array}{c}0.035 \\
(0.028)\end{array}$ & $\begin{array}{c}0.016 \\
(0.030)\end{array}$ \\
\hline Born abroad & $\begin{array}{c}0.026 \\
(0.033)\end{array}$ & $\begin{array}{c}0.134^{* * *} \\
(0.039)\end{array}$ & $\begin{array}{l}0.097 * \\
(0.046)\end{array}$ \\
\hline Good health & $\begin{array}{l}0.056^{*} \\
(0.026)\end{array}$ & $\begin{array}{c}0.020 \\
(0.030)\end{array}$ & $\begin{array}{c}0.036 \\
(0.034)\end{array}$ \\
\hline Aged 60 & Yes & Yes & Yes \\
\hline Single & Yes & Yes & Yes \\
\hline Employed & Yes & Yes & Yes \\
\hline Chronically ill & Yes & Yes & Yes \\
\hline Experience with public health services & Yes & Yes & Yes \\
\hline Regional variables ${ }^{1}$ & Yes & Yes & Yes \\
\hline Constant & $\begin{array}{c}-0.121 \text { * } \\
(0.053)\end{array}$ & $\begin{array}{l}-0.112 \\
(0.058)\end{array}$ & $\begin{array}{c}-0.184^{* *} \\
(0.066)\end{array}$ \\
\hline Observations & 6252 & 5854 & 4702 \\
\hline $\mathrm{R}^{2}$ & 0.537 & 0.422 & 0.431 \\
\hline
\end{tabular}

Note: Probit-adapted ordinary least squares regression. Entries show parameter estimates with robust standard errors in parenthesis. 'Yes' indicates that the variables have been included in the model, but their coefficients were not statistically significant in any of the regressions. ${ }^{1}$ Some coefficients of the region dummies (16 dummies) were significant but have not been included for the sake of brevity. ${ }^{* * *} p<0.001 ;{ }^{* *} p<0.01 ;{ }^{*} p<0.05$. 
More specifically, when focusing on the quantitative importance of the correlations (absolute value of the coefficients), not all of the correlations were found to have the same effect on self-reported experience with the health service. In primary care, for instance, we found that both treatment received from health staff (treatment received) and confidence and security transmitted by the doctor (confidence and security) showed the highest correlation, thus indicating that these factors contributed most to people reporting a more satisfactory experience with that health service. The Wald test of equality of the estimated parameters revealed that both coefficients were statistically equal $(\mathrm{F}[1,6214]=1.30$; $p=0.3525)$, but different from the third one $(\mathrm{F}[1,6214]=4.93 ; p=0.0264)$. From a statistical point of view, four non-clinical factors in specialised care had a similar quantitative importance on self-reported experience with the service as a whole, namely time devoted by the doctor, treatment received, confidence and security, and waiting time for diagnostic tests (Wald joint test of equality of estimated parameters: $\mathrm{F}[2,5818]=0.89, p=0.4087)$. Finally, in hospital care, three non-clinical factors, waiting time for non-emergency admission, information received on health problems, and care and attention by medical staff showed the highest association for self-reported experience with the service in similar quantitative terms (Wald joint test of equality of estimated parameters: $\mathrm{F}[2,4667]=0.30, p=0.7404$ ).

Regarding the socioeconomic variables, for the sake of simplicity, in Table 6 we omitted the coefficients of the socioeconomic variables, which were not significant for any of the three health services. This was the case of age, marital status, employment status, chronic illness, and experience. In line with the literature [33,34], our findings indicated that some individuals' socioeconomic characteristics were correlated with self-reported experience of the health service. For example, gender was statistically significant only for primary care. Additionally, females reported a more satisfactory experience with primary care than males, which may be due to the utilisation patterns of the services [35]. Regarding educational level, people with a higher education reported a worse overall experience with primary and hospital care services, perhaps because of their higher expectations [36]. Respondents living in urban areas (towns with more than 10,000 inhabitants) tended to report a better overall experience in primary care. People born outside of Spain assessed their overall experience with the specialised and hospital care services better than those born in Spain, which may be explained by the 'happy migrant effect', that is, people from other countries tend to minimise the negative effect of their care and are usually more satisfied with the care they receive than nationals [37]. Finally, people with self-reported good health indicated a better experience with primary care.

\section{Conclusions}

Our findings showed that individuals' interaction with non-clinical factors was significantly associated with a satisfactory self-reported experience with the main Spanish health services. Therefore, health policy-makers should not only focus on the medical or technical aspects of healthcare, but also on non-clinical factors to ensure that people have a more satisfactory experience with the health services. This is a key finding because, as the literature has emphasised, improving responsiveness has positive effects on people's health.

The results of our study indicate that not all non-clinical factors correlate in the same manner with the self-reported experience with the health services. For each health service, we identified where the scarce public resources could be targeted to ensure people have a more satisfactory experience with the analysed health service. More specifically, based on our findings in primary care, it is important to improve the treatment and confidence and security transmitted by the health staff. In specialised care, our results suggest that it is necessary to increase the time doctors devote to each patient, enhance the treatment received, improve the confidence and security transmitted by the health staff, and reduce the waiting times for diagnostic tests. It is worth highlighting that there is more room for improvement in waiting times for diagnostic tests and time devoted by doctors, since they are the items with which people are least satisfied, as indicated by the scores for these two factors (5 and 6.7, respectively).

Finally, in hospital care, it would be convenient to reduce the waiting times for non-emergency admission, provide patients with better information about their health problems, and improve the care 
and attention delivered by medical staff. If we look more closely at the results for hospital care, despite the importance of waiting times for non-emergency admissions as a driver of a more satisfactory self-reported experience, our findings showed that this service received the lowest rating for this non-clinical factor, with an average score of 4.8 out of 10. This low score could explain, at least partially, why hospital care in Spain is the most poorly rated health service by people (an average score of 6.5).

Likewise, these results indicate that in the Spanish case, the key factors of experience are related to respect for people, which is not so dependent on economic resources [38]. For instance, ensuring respectful treatment by the health staff only requires developing certain personal skills that could be fostered through better training in higher education programmes. Conversely, improving waiting times or increasing the time devoted to each patient could be more resource demanding since more health staff or amenities would be needed. To sum up, policy-makers should consider the type of financing, the way in which the resources are combined, and the development of strategies for generating resources that could contribute to ensuring a better attainment of crucial non-clinical factors [39].

Regarding the limitations of our study, it is worth noting that, due to the lack of data, we have not been able to include other non-clinical factors that could be associated with self-reported experience, nor have we been able to analyse the same factors in all health services. Furthermore, due to cultural idiosyncrasies as well as differences in the conception of the welfare state across populations, it would not be appropriate to extrapolate these results to other countries. For this reason, further studies that examine the influence of non-clinical factors on performance in different settings as well as from a dynamic perspective over time are needed.

Author Contributions: Both authors contributed equally and fully to all aspects of this manuscript. All authors have read and agreed to the published version of the manuscript.

Funding: This research was funded by the Spanish Ministry of Economy, Industry and Competitiveness, and the European Regional Fund, grant number ECO2015-66553-R. Ángel Fernández-Pérez is supported by the Spanish Ministry of Economy (FPI 2016 BES-2016-076476).

Conflicts of Interest: The authors declare no conflicts of interest.

\section{References}

1. WHO. The World Health Report 2000-Health Systems: Improving Performance; World Health Organization: Geneva, Switzerland, 2000.

2. Fiorentini, G.; Robone, S.; Verzulli, R. How do hospital-specialty characteristics influence health system responsiveness? An empirical evaluation of in-patient care in the Italian region of Emilia-Romagna. Health Econ. 2018, 27, 266-281. [CrossRef] [PubMed]

3. Rahman, M.H.U.; Singh, A.; Madhavan, H. Disability-based disparity in outpatient health system responsiveness among the older adults in low- to upper-middle-income countries. Health Policy Plan. 2019, 34, 141-150. [CrossRef] [PubMed]

4. Murante, A.M.; Seghieri, C.; Vainieri, M.; Schäfer, W.L.A. Patient-perceived responsiveness of primary care systems across Europe and the relationship with the health expenditure and remuneration systems of primary care doctors. Soc. Sci. Med. 2017, 186, 139-147. [CrossRef] [PubMed]

5. Röttger, J.; Blümel, M.; Linder, R.; Busse, R. Health system responsiveness and chronic disease care-What is the role of disease management programs? An analysis based on cross-sectional survey and administrative claims data. Soc. Sci. Med. 2017, 185, 54-62. [CrossRef] [PubMed]

6. Valentine, N.B.; De Silva, A.; Kawabata, K.; Darby, C.; Murray, C.J.L.; Evans, D.B. Health system responsiveness: Concepts, domains and operationalization. In Health Systems Performance Assessment: Debates, Methods and Empiricism; Murray, C.J.L., Evans, D.B., Eds.; World Health Organization: Geneva, Switzerland, 2003; pp. 573-596.

7. Kamra, V.; Singh, H.; Kumar De, K. Factors affecting patient satisfaction: An exploratory study for quality management in the health-care sector. Total Qual. Manag. Bus. Excell. 2016, 27, 1013-1027. [CrossRef] 
8. Valentine, N.B.; Bonsel, G.J.; Murray, C.J.L. Measuring quality of health care from the user's perspective in 41 countries: Psychometric properties of WHO's questions on health systems responsiveness. Qual. Life Res. 2007, 16, 1107-1125. [CrossRef]

9. Bleich, S.N.; Özaltin, E.; Murray, C.J.L. How does satisfaction with the health-care system relate to patient experience? Bull. World Health Organ. 2009, 87, 271-278. [CrossRef]

10. Sofaer, S.; Firminger, K. Patient perceptions of the quality of health services. Annu. Rev. Public Health 2005, 26, 513-559. [CrossRef]

11. Naidu, A. Factors affecting patient satisfaction and healthcare quality. Int. J. Health Care Qual. Assur. 2009, 22, 366-381. [CrossRef]

12. Banerjee, A.V.; Duflo, E. Poor Economics: A radical Rethinking of the Way to Fight Global Poverty; PublicAffairs: New York, NY, USA, 2011.

13. Gostin, L.; Hodge, J.G.; Valentine, N.; Nygren-Krug, H. The domains of health responsiveness. A Human Rights analysis. Heal. Hum. Rights Work. Pap. Ser. 2003, 2, 1-12.

14. Bacigalupe, A.; Martín, U.; Font, R.; González-Rábago, Y.; Bergantiños, N. Austeridad y privatización sanitaria en época de crisis: ¿existen diferencias entre las comunidades autónomas? Respuesta. Gac. Sanit. 2016, 30, 321. [CrossRef] [PubMed]

15. WHO. Economic Crisis, Health Systems and Health in Europe; Maresso, A., Mladovsky, P., Thomson, S., Sagan, A., Karanikolos, M., Richardson, E., Cylus, J., Evetovits, T., Jowett, M., Figueras, J., et al., Eds.; World Health Organization: Geneva, Switzerland, 2015; ISBN 9789289050340.

16. Bernal-Delgado, E.; García-Armesto, S.; Oliva, J.; Sánchez Martínez, F.I.; Repullo, J.R.; Peña-Longobardo, L.M.; Ridao-López, M.; Hernández-Quevedo, C. Spain: Health system review. Eur. Obs. Heal. Syst. Policies 2018, 20,1-179.

17. Serrano-del-Rosal, R.; Loriente-Arín, N. La anatomía de la satisfacción del paciente. Salud Publica Mex. 2008, 50, 162-172. [CrossRef]

18. Más, A.; Parra, P.; Bermejo, R.M.; Hidalgo, M.D.; Calle, J.E. Improving quality in healthcare: What makes a satisfied patient? Rev. Calid. Asist. 2016, 31, 196-203. [CrossRef] [PubMed]

19. Fontova-Almató, A.; Juvinyà-Canal, D.; Suñer-Soler, R. Influencia del tiempo de espera en la satisfacción de pacientes y acompañantes. Rev. Calid. Asist. 2015, 30, 10-16. [CrossRef] [PubMed]

20. Patricio Bustamante, P.; Avendaño Cañas, D.; Camacho Martín, B.; Ochoa Alvarado, E.; Alemany González, F.X.; Asenjo Romero, M.; Mohammad Tariq, K.; Sánchez Sánchez, M. Evaluación de la satisfacción del paciente con la atención recibida en un servicio de urgencias hospitalario y sus factores asociados. Emergencias 2013, 25, 171-176.

21. Blanco-Abril, S.; Sánchez-Vicario, F.; Chinchilla-Nevado, M.A.; Cobrero-Jimenez, E.M.; Mediavilla-Durango, M.; Rodríguez-Gonzalo, A.; Cuñado-Barrio, A. Satisfacción de los pacientes de urgencias con los cuidados enfermeros. Enfermería Clínica 2010, 20, 23-31. [CrossRef]

22. Quintana, J.M.; Gonzalez, N.; Bilbao, A.; Aizpuru, F.; Escobar, A.; Esteban, C.; San-Sebastian, J.A.; De-la-Sierra, E.; Thompson, A. Predictors of patient satisfaction with hospital health care. BMC Health Serv. Res. 2006, 6, 102. [CrossRef]

23. Valls Martínez, M.D.C.; Abad Segur, E. Patient satisfaction in the Spanish National Health System. An. Sist. Sanit. Navar. 2018, 41, 309-320.

24. Wang, W.; Maitland, E.; Nicholas, S.; Haggerty, J. Determinants of overall satisfaction with public clinics in rural China: Interpersonal care quality and treatment outcome. Int. J. Environ. Res. Public Health 2019, 16, 679. [CrossRef]

25. Hussain, A.; Sial, M.S.; Usman, S.M.; Hwang, J.; Jiang, Y.; Shafiq, A. What factors affect patient satisfaction in public sector hospitals: Evidence from an emerging economy. Int. J. Environ. Res. Public Health 2019, 16, 994. [CrossRef] [PubMed]

26. Nunu, W.N.; Munyewende, P.O. Patient satisfaction with nurse-delivery primary health care services in Free State and Gauteng provinces, South Africa: A comparative study. African J. Prim. Heal. Care Fam. Med. 2017, 9, 1-8. [CrossRef] [PubMed]

27. Van Praag, B.M.S.; Ferrer-i-Carbonell, A. Happiness Quantified: A Satisfaction Calculus Approach; Oxford University Press: Oxford, UK, 2008.

28. Bárcena-Martín, E.; Cortés-Aguilar, A.; Moro-Egido, A.I. Social comparisons on subjective well-being: The role of social and cultural capital. J. Happiness Stud. 2017, 18, 1121-1145. [CrossRef] 
29. Blázquez Cuesta, M.; Budría, S. Deprivation and Subjective Well-Being: Evidence from Panel Data. Rev. Income Wealth 2014, 60, 655-682.

30. Navarro, M.; Salverda, W. Earner position and job and life satisfaction: Do contributions to the household income have the same effect by gender and occupations? J. Happiness Stud. 2019, 20, 2227-2250. [CrossRef]

31. Green, C.P.; Heywood, J.S. Dissatisfied union workers: Sorting revisited. Br. J. Ind. Relations 2015, 53, 580-600. [CrossRef]

32. Gandelman, N.; Piani, G.; Ferre, Z. Neighborhood determinants of quality of life. J. Happiness Stud. 2012, 13, 547-563. [CrossRef]

33. Ali, F.M.H.; Nikoloski, Z.; Reka,H. Satisfaction and responsiveness with health-care services in Qatar-evidence from a survey. Health Policy (N. Y.) 2015, 119, 1499-1505. [CrossRef]

34. Fiorentini, G.; Ragazzi, G.; Robone, S. Are bad health and pain making us grumpy? An empirical evaluation of reporting heterogeneity in rating health system responsiveness. Soc. Sci. Med. 2015, 144, 48-58. [CrossRef]

35. Park, K.; Park, J.; Kwon, Y.D.; Kang, Y.; Noh, J.-W. Public satisfaction with the healthcare system performance in South Korea: Universal healthcare system. Health Policy (N. Y.) 2016, 120, 621-629. [CrossRef]

36. Muntlin, Å.M.-Y.; Gunningberg, L.A.-C.; Carlsson, M.A. Different patient groups request different emergency care-A survey in a Swedish emergency department. Int. Emerg. Nurs. 2008, 16, 223-232. [CrossRef] [PubMed]

37. Garrett, P.W.; Dickson, H.G.; Young, L.; Whelan, A.K. “The Happy Migrant Effect": Perceptions of negative experiences of healthcare by patients with little or no English. A qualitative study across seven language groups. Qual. Saf. Health Care 2008, 17, 101-103. [CrossRef] [PubMed]

38. De Silva, A. A framework for measuring responsiveness. World Heal. Organ. 2000, 32, 1-42.

39. Murray, C.J.L.; Evans, D.B. Health systems performance assessment: Goals, framework and overview. In Health System Performance: Debates, Met Hods and Empiricism; Murray, C.J.L., Evans, D.B., Eds.; World Health Organization: Geneva, Switzerland, 2003; pp. 3-22.

(C) 2019 by the authors. Licensee MDPI, Basel, Switzerland. This article is an open access article distributed under the terms and conditions of the Creative Commons Attribution (CC BY) license (http://creativecommons.org/licenses/by/4.0/). 